\title{
Marginal Integrity of Composite Restoration with and without Surface Pretreatment by Gold and Silver Nanoparticles vs Chlorhexidine: A Randomized Controlled Trial
}

\author{
Aya AEM Nemt-Allah ${ }^{1}$, Shereen $\mathrm{H}_{\text {Ibrahim }}^{2}$, Amira F El-Zoghby ${ }^{3}$
}

\begin{abstract}
Aim: This study was conducted to evaluate the marginal adaptation, marginal staining, and postoperative sensitivity of resin composite restorations after disinfection of class II cavities with NanoCare Gold and chlorhexidine in class II cavities immediately, after 6 months, 1, and 2 years using World Dental Federation (FDI) criteria for assessment of dental restorations.

Materials and methods: In this study, 19 participants were recruited, 3 carious lesions in each one. After preparation of these lesions, they were randomly allocated into three parallel groups according to the disinfection protocol. The first group was for NanoCare Gold, the second was for chlorhexidine, and the third was for the control. The three groups were evaluated clinically and radiographically using (FDI) criteria at different intervals till 2 years of clinical service.

Results: There was no statistically significant difference in age, gender, arch, and tooth type distribution among study groups. Regarding marginal adaptation, there was no statistically significant difference among the different groups but the difference was only statistically significant within each group after 2 years. Regarding the marginal staining, the difference was only significant between the NanoCare and the other groups after 2 years. In case of postoperative sensitivity, there was no statistically significant difference among the different groups and within each one at different intervals.

Conclusion: NanoCare Gold could be promising in durability preservation of direct tooth-colored restorations. Marginal staining and postoperative sensitivity are regulated by other factors than surface pretreatment.

Clinical significance: As long as restorations are inserted under rubber dam isolation, proper application steps, proper filling, and adequate finishing and polishing, the performance of the restorations would be satisfactory up to 1 year without any surface disinfection. However, after a longer follow-up, some changes may be noticed. NanoCare Gold and chlorhexidine are accepted as a cavity disinfectant without any negative effect on marginal adaptation of resin composite restorations.

Keywords: Chlorhexidine, Marginal adaptation, Marginal staining, NanoCare Gold, Postoperative sensitivity.

The Journal of Contemporary Dental Practice (2021): 10.5005/jp-journals-10024-3200
\end{abstract}

\section{InTRODUCTION}

Histological nature of dentin is really challenging in bonding but interesting in attempts for preservation of durability. Achieving a hermetic seal between the interface of bonding surfaces is considered critical. Usually, a minute gap is present between these surfaces. This permits the ingress of bacteria and oral fluids, leading to caries recurrence and restoration failure and, hence, emphasizing the importance of hybrid layer and its quality. ${ }^{1}$ Hybrid layer is formed by the interaction of dentin substrate and adhesive system. These elements are the determining factors for quality and durability of this bond. ${ }^{2}$

Matrix metalloproteinases (MMPs) and cysteine cathepsins are the criminals in the destruction of the collagenous part of dentin involved in the hybrid layer. These enzymes are activated naturally during caries process and artificially during restorative procedures by the acidic monomer in adhesive systems. The prohibition of these active enzymes may help in the creation of a durable bond. ${ }^{3,4}$

Several materials are classified as inhibitors for collagenolytic enzymes in addition to their antibacterial effect. Chlorhexidine is considered the gold standard in this category. This is due to its ability to target not only MMPs but also cysteine cathepsins in addition to its antibacterial properties. Despite all of these advantages, its effect

\footnotetext{
1,2 Department of Conservative Dentistry, Faculty of Dentistry, Cairo University, Cairo, Egypt; Faculty of Dentistry, Egyptian Russian University, Badr, Egypt

${ }^{3}$ Department of Conservative Dentistry, Faculty of Dentistry, Cairo University, Cairo, Egypt

Corresponding Author: Shereen H Ibrahim, Department of Conservative Dentistry, Faculty of Dentistry, Cairo University, Cairo, Egypt; Faculty of Dentistry, Egyptian Russian University, Badr, Egypt, Phone: +201099296591, e-mail: shereen.hafez@dentistry.cu.edu.eg
}

How to cite this article: Nemt-Allah AAEM, Ibrahim SH, El-Zoghby AF. Marginal Integrity of Composite Restoration with and without Surface Pretreatment by Gold and Silver Nanoparticles vs Chlorhexidine: A Randomized Controlled Trial. J Contemp Dent Pract 2021;22(10): 1087-1097.

Source of support: Nil

Conflict of interest: None

on the previous enzymes is a short-term one. ${ }^{5}$ Hence, new materials are needed to cover the shortage of the older one.

Nowadays metallic nanoparticles like nanosilver (AgNPs) and nanogold (AuNPs) are gaining popularity in medical and dental fields. ${ }^{6}$ NanoCare Gold, a cavity disinfectant containing

(C) The Author(s). 2021 Open Access This article is distributed under the terms of the Creative Commons Attribution 4.0 International License (https://creativecommons. org/licenses/by-nc/4.0/), which permits unrestricted use, distribution, and non-commercial reproduction in any medium, provided you give appropriate credit to the original author(s) and the source, provide a link to the Creative Commons license, and indicate if changes were made. The Creative Commons Public Domain Dedication waiver (http://creativecommons.org/publicdomain/zero/1.0/) applies to the data made available in this article, unless otherwise stated. 
nanoparticles of Ag-Au suspended in isopropyl alcohol has been introduced into the market. The manufacturer claims that this disinfectant enhances the adhesion of resin composite to tooth structure and empowers the physical properties of the polymer in addition to the proven antibacterial properties. ${ }^{7}$

Considering conservatism principles, retention of posterior composite restorations depends mainly on the quality of adhesion and cavity configuration. Sometimes, restorations in class I or II cavities would not fall off their restored surfaces even in compromised adhesion. Because of that, the quality of adhesion in such cases is indirectly evaluated by parameters like marginal adaptation and marginal discoloration using FDI criteria. ${ }^{8-10}$

Reviewing the literature, NanoCare Gold has no negative effect on bond strength of resin composite to dentin but there are no published clinical trials confirming these results yet. ${ }^{4}$ Therefore, this study was performed to investigate its effect clinically on the marginal adaptation, marginal staining, and postoperative sensitivity of resin composite restorations in class II cavities. Restorations were evaluated immediately, after 6 months, 1, and 2 years using FDI criteria for assessment of dental restorations. The null hypothesis tested is that there is no difference among the NanoCare Gold, chlorhexidine, and the standard of care, regarding marginal adaptation, marginal staining, and postoperative sensitivity.

\section{Materials and Methods}

\section{Sample Size Calculation}

This power analysis used marginal adaptation score as the primary outcome. The effect sizes were $\mathrm{w} 1=0.8885$ and $\mathrm{w} 2=0.8498){ }^{11}$ Using alpha $(\alpha)$ level of $5 \%$ and beta $(\beta)$ level of $20 \%$ i.e., power $=80 \%$, the minimum estimated sample size was 15 subjects per group for a total of 45 subjects. The sample size was increased to 19 subjects per group (a total of 57 teeth) to compensate for a dropout rate of $25 \%$. Sample size calculation was performed using $\mathrm{G}^{*}$ Power version 3.1.9.2.

\section{Protocol Registration}

The protocol of the current study was registered in www. clinicaltrials.gov, with unique identification number NCT03669224. All procedures performed involving human participants were in accordance with the ethical standards of Research Ethics Committee of Faculty of Dentistry, Cairo University (CREC) \# 42-9-18.

\section{Study Design}

The study design included three parallel groups with 1:1 allocation ratio. The groups were divided according to the application of a cavity disinfectant or not. The first group was for NanoCare Gold, the second for chlorhexidine, and the third for the standard of care, which receives no surface pretreatment. Nineteen teeth were used in each group and the total number for all groups was 57 teeth. The restorations were evaluated regarding marginal adaptation, marginal staining, and postoperative sensitivity at different intervals, immediate evaluation, after 6 months, 1, and 2 years.

\section{Eligibility Criteria for Patients \\ Inclusion Criteria}

Participants eligible for the trial should have at least two class II cavities, good oral hygiene, and good general health. Cooperative participants of both genders were included as long as they accepted to sign the informed consent. Age frame lies between 17 and 50 years old.

\section{Exclusion Criteria}

Participants younger than 17 or older than 50 years old were excluded. Pregnant females, heavy smokers, participants with disabilities, or severe medical complications were also excluded.

\section{Eligibility Criteria for Teeth}

\section{Inclusion Criteria}

Any vital posterior tooth with no signs or symptoms of irreversible pulpitis or periapical pathosis was included. Functioning class II carious lesions with healthy periodontium was a must.

\section{Exclusion Criteria of Teeth}

Teeth with signs of pulpal, periapical pathosis, or endodontically treated were excluded. Nonfunctioning carious lesions other than class II, in heavy occlusion patients, and severe periodontal affection were also excluded.

\section{Recruitment}

Eligible participants were recruited from outpatient clinic of conservative dentistry department in Faculty of Dentistry, Cairo University. Signing the informed consent was mandatory.

At the same day of recruitment, radiographs, cavity preparation, cavity disinfection, restoration's insertion, immediate evaluation of marginal adaptation, marginal staining, and postoperative sensitivity were performed. Then each patient was recalled after 6 , 12 , and 24 months to evaluate the same aspects that were evaluated immediately.

\section{Radiography}

Teeth were radiographed digitally using Digora imaging software (100-240 VAC, 50/60 Hz operating voltage, $17 \mathrm{lp} / \mathrm{mm}$ resolution, 5-10 seconds readout time). Bitewing, parallel technique was followed using DIGORA intraoral imaging plate size 2 (SOREDEX, Finland) for the sake of standardization. Each tooth has preoperative (Fig. 1), immediate postoperative, and follow-up radiographs (6, 12, and 24 months).

\section{Randomization}

Simple randomization was performed for the prepared cavities to determine which tooth receives which intervention. Two different

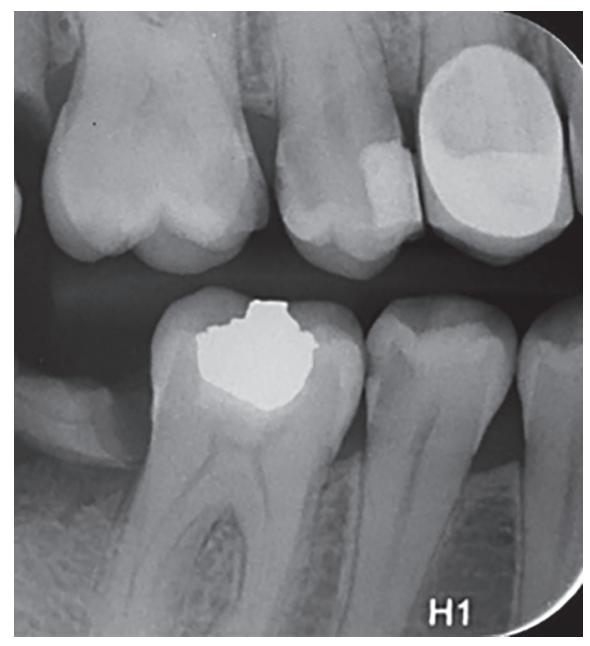

Fig. 1: Bitewing radiograph showing carious teeth (tooth of interest: tooth no 5, 6, upper right side) 
groups of colored papers were used. The first group contains the prepared tooth identification (e.g., lower right 6). The second group contained the applied materials (e.g., NanoCare Gold). One paper was selected haphazardly from the first group followed by another selection from the second one. This was performed by a blinded person not involved in the trial. The patients and assessors were blinded to the material assignment while the operator was not due to the difference in materials' presentation. $^{12}$

\section{Cavity Preparation}

All cavities and restorations were performed by the same operator. Assessment of centric and eccentric occlusal stops was performed with double-sided articulating paper prior to class II cavity preparation.

Cavities were of varying depth $(3 \mathrm{~mm}, 4,>4) \cdot{ }^{13,14}$ An extension for prevention was disregarded for maximum preservation of tooth structure; margins were not beveled. ${ }^{1}$ The cavities were prepared by 245 and 330 high speed burs under copious air and water coolant. Cavities walls were finished by yellow coded stones (ISO 198/018, TR-13EF). Any soft caries excavation in dentin was performed by sharp excavator (Maillefer, size 50/52, Dentsply) and the hard spots by a low speed round carbide bur of suitable size, compatible to the size of the carious spot (size 4, 5, or 6). Gingival marginal trimmer (GMT, Zefiro) was also used for any needed adjustments at the gingival seat. After completion of cavity preparation, quadrant rubber dam isolation was done (Fig. 2). All steps were documented by photographs (Nikon D5300, Nikon Macro-Lens 105).

\section{Materials' Application}

Scotchbond Universal Etchant (3M ESPE, USA) was applied to the enamel surface only for 15 seconds then rinsed with water for 15 seconds. Excess water was dried leaving the enamel surface chalky white. A small piece of wet cotton was applied over dentin to protect it from the etchant.

Five coats of NanoCare Gold (Dental Nanotechnology, Poland) were applied to dentin surface using micro brush directly after enamel etching. The bottle was shaken every time before use. The coats were left for 3 minutes for the natural evaporation of the solvent (Fig. 3). ${ }^{15}$

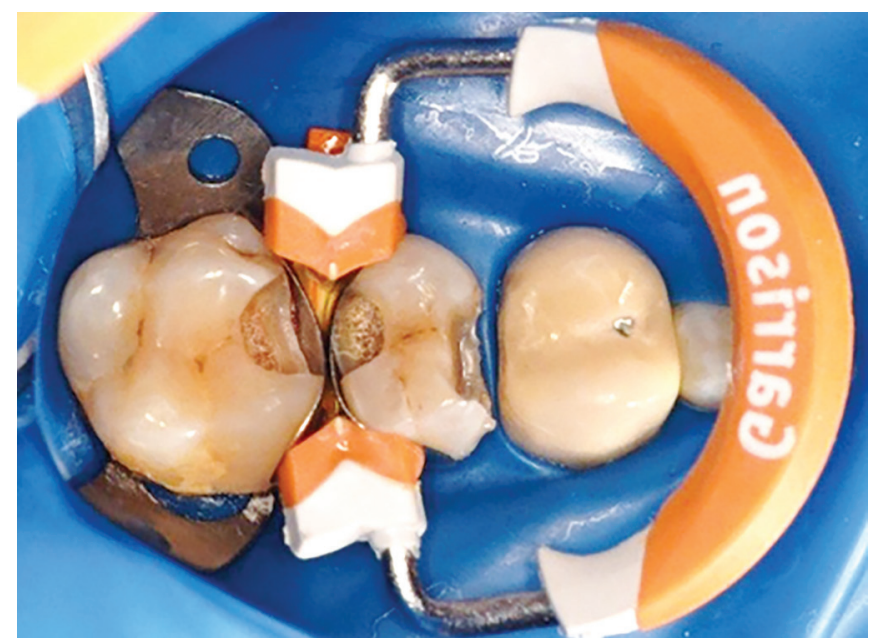

Fig. 2: Isolated prepared cavities with matricing and wedging (tooth of interest: tooth no 5, 6)
Consepsis ( $\mathrm{CHX}$, Ultradent, USA) was applied immediately after enamel etching for 1 minute then the excess was removed with cotton pellet (no rinsing) (Fig. 4).

Single Bond Universal Adhesive (3M ESPE, USA) was applied for 20 seconds with vigorous agitation followed by gentle air thinning for 5 seconds then light cured with LED light curing unit (CO2-C, Premium Plus International, Hong Kong) of intensity $1200 \mathrm{~mW} / \mathrm{cm}^{2}$ at zero distance for 10 seconds. The light intensity was regularly checked using a radiometer.

Filtek $^{\mathrm{TM}} \mathrm{Z350}$ XT packable resin composite (body shade A2, 3M ESPE, USA) was applied after matricing and wedging (Garrison, Composi-Tight 3D Fusion, USA) using centripetal technique. The rest of the cavity was filled by incremental oblique layers using plastic instrument (Elephant, Germany).

Each increment was polymerized for 20 seconds. After polymerization of the last layer, rechecking of tooth restoration interface was done by dental explorer and any visible overhang was removed with a scaler before removal of rubber dam. ${ }^{1}$ The occlusion was checked after restoration placement with double-

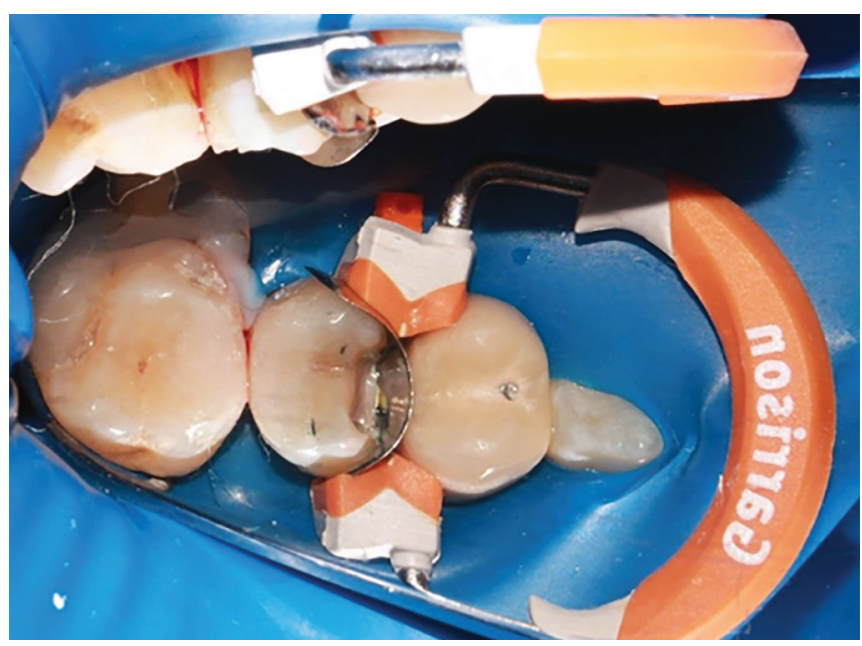

Fig. 3: NanoCare Gold inserted inside the cavity (tooth of interest: tooth no 5, mesial side)

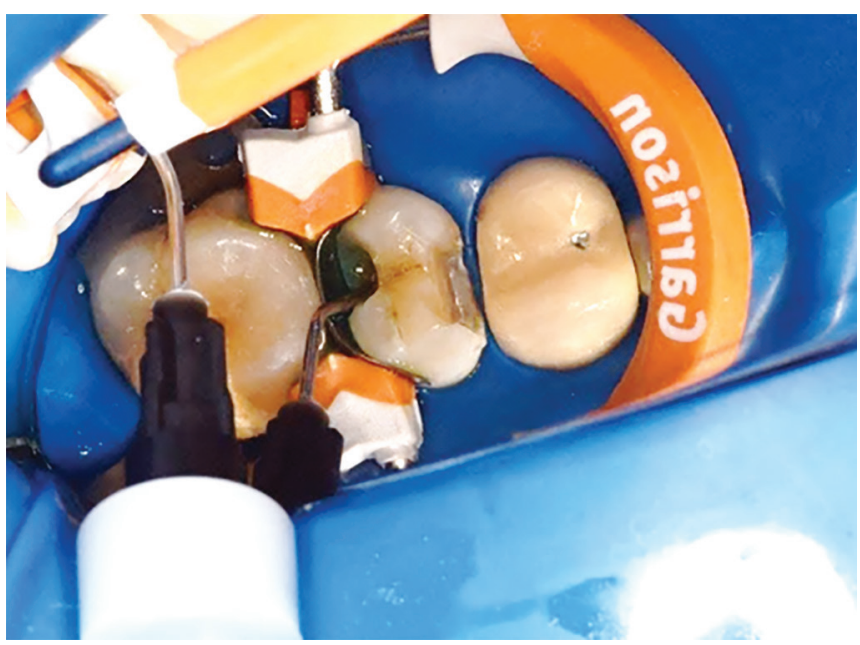

Fig. 4: Application of Consepsis inside the cavity (tooth of interest: tooth no 5, distal side) 
sided articulating paper. The proximal contact was checked using dental floss. The restorations were finished with white tapered abrasive bur and polished immediately by opti-brush (HiLuster PLUS ${ }^{\text {TM }}$, Kerr) after removal of rubber dam.

\section{Restorations' Evaluation}

Two experienced and calibrated assessors performed the evaluation. For training purpose, the examiners observed 10 photographs that were representative of each score for each criterion using a web-based training and calibration tool called e-calib. ${ }^{16}$ An intra-examiner and inter-examiner agreement of at least $85 \%$ was necessary before beginning the evaluation. Both examiners evaluated all the restorations once and independently. When disagreements happened during the evaluations, they had to reach a consensus before the participant was dismissed. ${ }^{12,17}$

The restorations were evaluated by FDI criteria at baseline (Fig. 5), 6 months, 1, and 2 years (Fig. 6) of clinical service. The primary clinical endpoint was marginal adaptation; the secondary endpoints were marginal staining and postoperative sensitivity.

To classify the marginal gaps, two special probes (Deppeler, Switzerland) were used with tip diameters of 150 and $250 \mu \mathrm{m}$. The depth of the gap should be at least the same size $(0.25 \mathrm{~mm})$, in addition to usage of digital radiograph to measure the hidden gap.
The status of the restoration fitted in one of the five categories in FDI scoring system for evaluation of marginal adaptation. ${ }^{8}$

Regarding marginal staining, the evaluation method was visual inspection and photographs which is reflected in FDI categorical scoring system that is divided into five categories.

Evaluation of the postoperative sensitivity was performed one week after the restorative procedure by applying a blast of cold air for 10 seconds from a dental triple airway syringe placed $2 \mathrm{~cm}$ from the occlusal surface of the tooth, and the patient was asked if there was sensitivity caused by the air jet or postoperative pain at some other time prior to the evaluation. ${ }^{12,18}$ Evaluation was reflected into FDI categorical scoring system. ${ }^{8}$

\section{Statistical Analysis}

Statistical analysis was performed using IBM SPSS Statistics Version 26 for Windows. Data were presented as frequencies ( $n$ ) and percentages (\%) for qualitative data; and mean and standard deviation (SD) for quantitative data. Kolmogorov-Smirnov and Shapiro-Wilk tests were used to assess data normality. For demographic data, the Chi-square test was used for intergroup comparisons of qualitative data, and independent Student $t$-test was used for quantitative data. Kruskal-Wallis was conducted to compare distribution of FDI scores between different surface
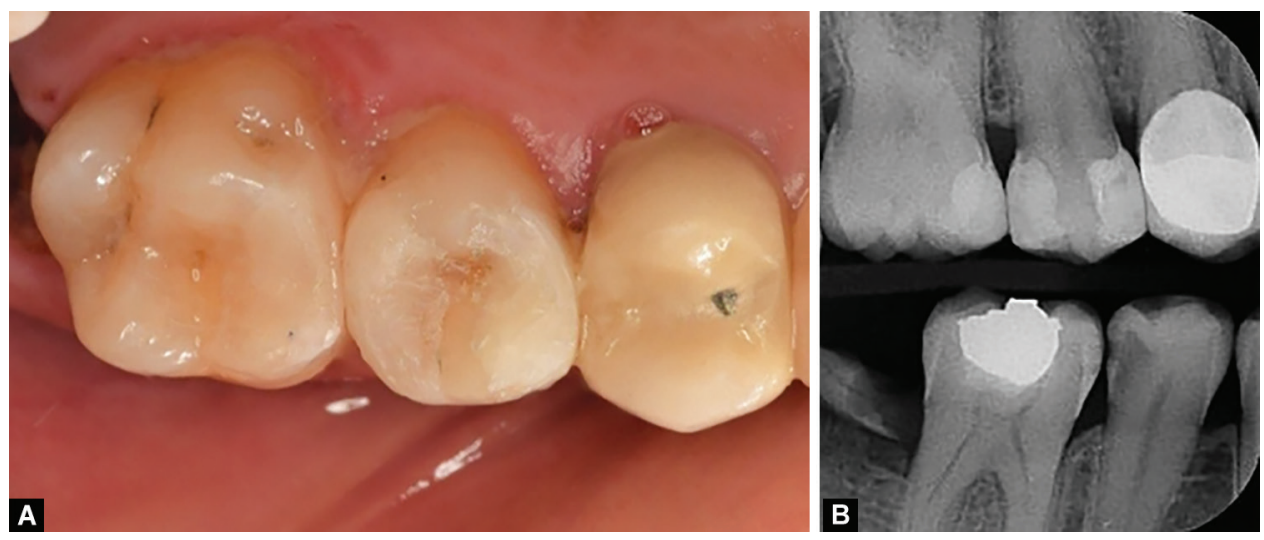

Figs 5A and B: (A) Intraoral photograph of (tooth of interest: tooth no 5 mesial and distal side, tooth no 6 , mesial side) after insertion of restorations; (B) Bitewing radiograph (tooth of interest: tooth no 5 mesial and distal side, tooth no 6 , mesial side) after insertion of restorations
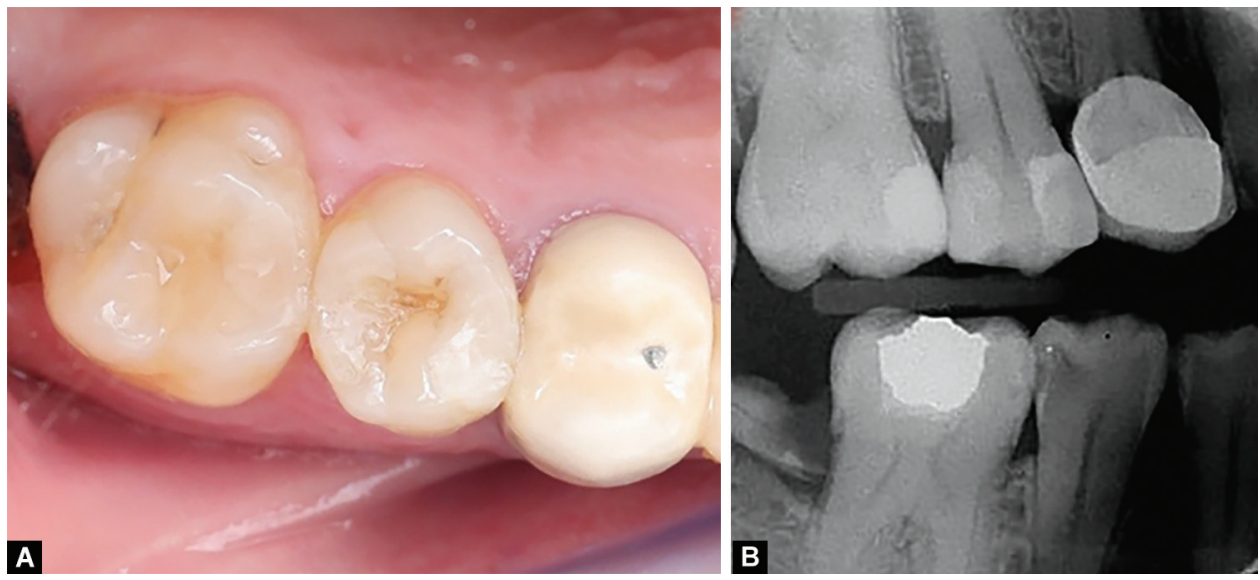

Figs 6A and B: (A): Intraoral photograph of (tooth of interest: tooth no 5 mesial and distal side, tooth no 6, mesial side) on 2 years follow-up; (B) Bitewing radiograph (tooth of interest: tooth no 5 mesial and distal side, tooth no 6, mesial side) on 2 years follow-up 
pretreatments at each interval. Friedman test was performed to compare FDI scores among different intervals within each group. Multiple comparisons were performed using Steel-Dwass test. The significance level was set at $p \leq 0.05$.

\section{RESULTS}

This clinical trial is formed of three groups. Nineteen teeth were employed for each group. These groups were evaluated using FDI criteria regarding marginal adaptation, marginal staining, and postoperative sensitivity. Evaluation was performed immediately, after 6 months, 1 , and 2 years.

\section{Demographic Data}

Mean, standard deviation (SD), frequencies (n), percentages (\%), and $p$-value for demographic data were presented in Table 1. The mean age of the 19 participants was $29.9 \pm 7.4$ years old. Seven were males (36.8\%) and 12 were females (63.2\%). Twenty-seven maxillary (47.4\%) and 30 mandibular (52.6\%) teeth were restored. Thirty-one restorations (54.4\%) were placed in premolars and 26 (45.6\%) were placed in molars. There was no statistically significant difference in age, gender, arch, and tooth type distribution among study groups $(p=0.896, p=1.000, p=0.399$, and $p=0.612$, respectively).

\section{Marginal Adaptation Using FDI Scoring System}

All restorations in all groups scored 1 till the first year as presented in Table 2. There was no statistically significant difference in distribution of FDI scores among different groups ( $p=1.000$ for immediately, 6 months and 12 months, and $p=0.188$ ). On the contrary, there was a statistically significant difference in distribution of FDI scores among different intervals within each group ( $p<0.001$ within control group, $p=0.007$ within NanoCare Gold group, and $p<0.001$ within chlorhexidine group). After 24 months, all groups showed higher score of $2 \%$.

\section{Marginal Staining Using FDI Scoring System}

There was no statistically significant difference among the different groups and within each group till 1 year as presented in Table 3. After 2 years, there was a statistically significant difference among the different groups. The NanoCare group showed no marginal stains after 2 years. The other groups showed a statistically significant difference with their own previous scores and with NanoCare Gold group.

\section{Postoperative Hypersensitivity Using FDI Scoring System}

There was no statistically significant difference among the different groups and within the same group at different intervals as presented in Table 4.

\section{Discussion}

Although adhesive restorations show acceptable survival rates, huge amount of time and money are wasted on replacement of failed restorations. The failure rate ranges from 15 to $50 \%$. The most common reasons for failure are fracture, secondary caries, marginal deficiencies, wear, and postoperative sensitivity, while fracture is assumed to occur early, secondary caries occurs later within the function period of the restoration. ${ }^{19}$

It has been reported that bonding strength to dentin decreases $30-40 \%$ after 6 months and $60-70 \%$ after 1 year. ${ }^{20}$ Degradation of the hybrid layer could be broadly divided into two major categories: hydrolytic degradation of the collagen matrix and hydrolytic degradation of the adhesive within the hybrid layer (the resinous part in the form of plasticization). ${ }^{21,22}$

In this study, the used universal adhesive represents a type of self-etching (SE) adhesives. The durability and stability of bonded interfaces created by this adhesive continue to be questionable. One of the advantages of using the universal adhesive in the clinical routine would be allowing the clinician to choose the type of application protocol according to the clinical situation, optimizing the final result of the procedure. ${ }^{18}$

Using multimode adhesive in self-etch mode, in both noncarious and carious lesions, led to marginal discoloration or degradation of marginal adaptation in 18-24-month clinical follow-up. ${ }^{23}$ Selective enamel etch followed by the application of a mild universal adhesive appears to be the best choice to effectively achieve a durable bond to tooth tissues in the form of better esthetic, functional sealing and reduced marginal discoloration and improved adaptation. The problem that we may face with this technique is that the clinician may unintentionally etch the dentin. In this condition, bond strength may decrease when self-etch adhesives are applied on acid-etched dentin when compared with the same adhesive applied in the self-etch mode. ${ }^{17,18,24}$

The remaining bacteria are one of the contributing factors in caries recurrence that's why the prohibition of these bacteria is mandatory. It has been proven that the remaining bacteria may survive and multiply up to 139 days after insertion of restoration

Table 1: Mean \pm SD, frequencies $(n)$, percentages $(\%)$, and $p$-value for demographic data

\begin{tabular}{lccccc}
\hline $\begin{array}{l}\text { Demographic } \\
\text { data }\end{array}$ & $\begin{array}{c}\text { Total } \\
(N=57)\end{array}$ & $\begin{array}{c}\text { Control } \\
(N=19)\end{array}$ & $\begin{array}{c}\text { NanoCare Gold } \\
(N=19)\end{array}$ & $\begin{array}{c}\text { Chlorhexidine } \\
(N=19)\end{array}$ & p value \\
\hline Age (years) & $29.9 \pm 7.4$ & $29.9 \pm 7.4$ & $29.9 \pm 7.4$ & $29.9 \pm 7.4$ & $1.000 \mathrm{NS}$ \\
$\begin{array}{l}\text { Gender } \\
\text { Male }\end{array}$ & $21(36.8 \%)$ & $7(36.8 \%)$ & $7(36.8 \%)$ & $7(36.8 \%)$ & \\
$\quad \begin{array}{l}\text { Female } \\
\text { Arch }\end{array}$ & $36(63.2 \%)$ & $12(63.2 \%)$ & $12(63.2 \%)$ & $12(63.2 \%)$ & $1.000 \mathrm{NS}$ \\
$\quad$ Maxilla & $27(47.4 \%)$ & $10(52.6 \%)$ & $9(47.4 \%)$ & $8(42.1 \%)$ & $0.399 \mathrm{NS}$ \\
$\quad$ Mandible & $30(52.6 \%)$ & $9(47.4 \%)$ & $10(52.6 \%)$ & $11(57.9 \%)$ & \\
$\begin{array}{l}\text { Tooth type } \\
\text { Premolar }\end{array}$ & $31(54.4 \%)$ & $11(57.9 \%)$ & $12(63.2 \%)$ & $8(42.1 \%)$ & $0.612 \mathrm{NS}$ \\
$\quad$ Molar & $26(45.6 \%)$ & $8(42.1 \%)$ & $7(36.8 \%)$ & $11(57.9 \%)$ & \\
\hline
\end{tabular}

NS, nonsignificant at $p>0.05$ 
Table 2: Frequency ( $n / \%)$ of FDI scores for marginal adaptation

\begin{tabular}{|c|c|c|c|c|c|c|c|}
\hline \multirow[b]{2}{*}{ Adaptation } & \multicolumn{2}{|c|}{ Control } & \multicolumn{2}{|c|}{ Nano } & \multicolumn{2}{|c|}{ ChX } & \multirow[b]{2}{*}{$p$ value } \\
\hline & $n$ & $\%$ & $n$ & $\%$ & $n$ & $\%$ & \\
\hline \multicolumn{8}{|c|}{$\operatorname{Imm}(n=19)$} \\
\hline Score 1 & 19 & $100.0 \%$ & 19 & $100.0 \%$ & 19 & $100.0 \%$ & $1.00 \mathrm{NS}$ \\
\hline Score 2 & 0 & $0.0 \%$ & 0 & $0.0 \%$ & 0 & $0.0 \%$ & \\
\hline Score 3 & 0 & $0.0 \%$ & 0 & $0.0 \%$ & 0 & $0.0 \%$ & \\
\hline Score 4 & 0 & $0.0 \%$ & 0 & $0.0 \%$ & 0 & $0.0 \%$ & \\
\hline Score 5 & 0 & $0.0 \%$ & 0 & $0.0 \%$ & 0 & $0.0 \%$ & \\
\hline Rank & \multicolumn{2}{|c|}{$\mathrm{aA}$} & \multicolumn{2}{|c|}{$\mathrm{aA}$} & \multicolumn{2}{|c|}{$\mathrm{aA}$} & \\
\hline \multicolumn{8}{|l|}{$6 \mathrm{M}(n=17)$} \\
\hline Score 1 & 17 & $100.0 \%$ & 17 & $100.0 \%$ & 17 & $100.0 \%$ & $1.00 \mathrm{NS}$ \\
\hline Score 2 & 0 & $0.0 \%$ & 0 & $0.0 \%$ & 0 & $0.0 \%$ & \\
\hline Score 3 & 0 & $0.0 \%$ & 0 & $0.0 \%$ & 0 & $0.0 \%$ & \\
\hline Score 4 & 0 & $0.0 \%$ & 0 & $0.0 \%$ & 0 & $0.0 \%$ & \\
\hline Score 5 & 0 & $0.0 \%$ & 0 & $0.0 \%$ & 0 & $0.0 \%$ & \\
\hline Rank & \multicolumn{2}{|c|}{$\mathrm{aA}$} & \multicolumn{2}{|c|}{$\mathrm{aA}$} & \multicolumn{2}{|c|}{$\mathrm{aA}$} & \\
\hline \multicolumn{8}{|c|}{$12 \mathrm{M}(n=15)$} \\
\hline Score 1 & 15 & $100.0 \%$ & 15 & $100.0 \%$ & 15 & $100.0 \%$ & $1.00 \mathrm{NS}$ \\
\hline Score 2 & 0 & $0.0 \%$ & 0 & $0.0 \%$ & 0 & $0.0 \%$ & \\
\hline Score 3 & 0 & $0.0 \%$ & 0 & $0.0 \%$ & 0 & $0.0 \%$ & \\
\hline Score 4 & 0 & $0.0 \%$ & 0 & $0.0 \%$ & 0 & $0.0 \%$ & \\
\hline Score 5 & 0 & $0.0 \%$ & 0 & $0.0 \%$ & 0 & $0.0 \%$ & \\
\hline Rank & \multicolumn{2}{|c|}{$\mathrm{aA}$} & \multicolumn{2}{|c|}{$\mathrm{aA}$} & \multicolumn{2}{|c|}{$\mathrm{aA}$} & \\
\hline \multicolumn{8}{|c|}{$24 \mathrm{M}(n=15)$} \\
\hline Score 1 & 8 & $53.3 \%$ & 11 & $73.3 \%$ & 6 & $40.0 \%$ & $0.188 \mathrm{NS}$ \\
\hline Score 2 & 7 & $46.7 \%$ & 4 & $26.7 \%$ & 9 & $60.0 \%$ & \\
\hline Score 3 & 0 & $0.0 \%$ & 0 & $0.0 \%$ & 0 & $0.0 \%$ & \\
\hline Score 4 & 0 & $0.0 \%$ & 0 & $0.0 \%$ & 0 & $0.0 \%$ & \\
\hline Score 5 & 0 & $0.0 \%$ & 0 & $0.0 \%$ & 0 & $0.0 \%$ & \\
\hline Rank & \multicolumn{2}{|c|}{$\mathrm{bA}$} & \multicolumn{2}{|c|}{$\mathrm{bA}$} & \multicolumn{2}{|c|}{$\mathrm{bA}$} & \\
\hline$p$ value & \multicolumn{2}{|c|}{$<0.001^{*}$} & \multicolumn{2}{|c|}{$0.007^{*}$} & \multicolumn{2}{|c|}{$<0.001^{*}$} & \\
\hline
\end{tabular}

* Significant; NS, nonsignificant. Different uppercase letters within each row indicate significant difference. While different lowercase letters indicate significant difference within each column

Table 3: Frequency ( $n / \%)$ of FDI scores for marginal staining

\begin{tabular}{|c|c|c|c|c|c|c|c|}
\hline \multirow[b]{2}{*}{ Staining } & \multicolumn{2}{|c|}{ Control } & \multicolumn{2}{|c|}{ Nano } & \multicolumn{2}{|c|}{$\operatorname{ChX}$} & \multirow[b]{2}{*}{ pvalue } \\
\hline & $n$ & $\%$ & $n$ & $\%$ & $n$ & $\%$ & \\
\hline \multicolumn{8}{|c|}{$\operatorname{Imm}(n=19)$} \\
\hline Score 1 & 19 & $100.0 \%$ & 19 & $100.0 \%$ & 19 & $100.0 \%$ & $1.00 \mathrm{NS}$ \\
\hline Score 2 & 0 & $0.0 \%$ & 0 & $0.0 \%$ & 0 & $0.0 \%$ & \\
\hline Score 3 & 0 & $0.0 \%$ & 0 & $0.0 \%$ & 0 & $0.0 \%$ & \\
\hline Score 4 & 0 & $0.0 \%$ & 0 & $0.0 \%$ & 0 & $0.0 \%$ & \\
\hline Score 5 & 0 & $0.0 \%$ & 0 & $0.0 \%$ & 0 & $0.0 \%$ & \\
\hline Rank & \multicolumn{2}{|c|}{$\mathrm{aA}$} & \multicolumn{2}{|c|}{$\mathrm{aA}$} & \multicolumn{2}{|c|}{$\mathrm{aA}$} & \\
\hline \multicolumn{8}{|c|}{$6 \mathrm{M}(n=17)$} \\
\hline Score 1 & 15 & $88.2 \%$ & 13 & $76.5 \%$ & 13 & $76.5 \%$ & 0.614 NS \\
\hline Score 2 & 2 & $11.8 \%$ & 4 & $23.5 \%$ & 4 & $23.5 \%$ & \\
\hline Score 3 & 0 & $0.0 \%$ & 0 & $0.0 \%$ & 0 & $0.0 \%$ & \\
\hline Score 4 & 0 & $0.0 \%$ & 0 & $0.0 \%$ & 0 & $0.0 \%$ & \\
\hline Score 5 & 0 & $0.0 \%$ & 0 & $0.0 \%$ & 0 & $0.0 \%$ & \\
\hline Rank & \multicolumn{2}{|c|}{$\mathrm{aA}$} & \multicolumn{2}{|c|}{$\mathrm{aA}$} & \multicolumn{2}{|c|}{$\mathrm{aA}$} & \\
\hline
\end{tabular}




\begin{tabular}{|c|c|c|c|c|c|c|c|}
\hline \multicolumn{8}{|c|}{$12 \mathrm{M}(n=15)$} \\
\hline Score 1 & 11 & $73.3 \%$ & 12 & $80.0 \%$ & 11 & $73.3 \%$ & 0.889 NS \\
\hline Score 2 & 4 & $26.7 \%$ & 3 & $20.0 \%$ & 4 & $26.7 \%$ & \\
\hline Score 3 & 0 & $0.0 \%$ & 0 & $0.0 \%$ & 0 & $0.0 \%$ & \\
\hline Score 4 & 0 & $0.0 \%$ & 0 & $0.0 \%$ & 0 & $0.0 \%$ & \\
\hline Score 5 & 0 & $0.0 \%$ & 0 & $0.0 \%$ & 0 & $0.0 \%$ & \\
\hline Rank & \multicolumn{2}{|c|}{$\mathrm{aA}$} & \multicolumn{2}{|c|}{$\mathrm{aA}$} & \multicolumn{2}{|c|}{$\mathrm{aA}$} & \\
\hline \multicolumn{8}{|c|}{$24 \mathrm{M}(n=15)$} \\
\hline Score 1 & 9 & $60.0 \%$ & 15 & $100.0 \%$ & 9 & $60.0 \%$ & $0.018^{*}$ \\
\hline Score 2 & 6 & $40.0 \%$ & 0 & $0.0 \%$ & 6 & $40.0 \%$ & \\
\hline Score 3 & 0 & $0.0 \%$ & 0 & $0.0 \%$ & 0 & $0.0 \%$ & \\
\hline Score 4 & 0 & $0.0 \%$ & 0 & $0.0 \%$ & 0 & $0.0 \%$ & \\
\hline Score 5 & 0 & $0.0 \%$ & 0 & $0.0 \%$ & 0 & $0.0 \%$ & \\
\hline Rank & \multicolumn{2}{|c|}{$a B$} & \multicolumn{2}{|c|}{$\mathrm{aA}$} & \multicolumn{2}{|c|}{$a B$} & \\
\hline$p$ value & \multicolumn{2}{|c|}{0.058 NS } & \multicolumn{2}{|c|}{0.063 NS } & \multicolumn{2}{|c|}{0.112 NS } & \\
\hline
\end{tabular}

${ }^{*}$ Significant; NS, nonsignificant. Different uppercase letters within each row indicate significant difference. While different lowercase letters indicate significant difference within each column $(p>0.05)$

Table 4: Frequency ( $n / \%)$ of FDI scores for postoperative sensitivity

\begin{tabular}{|c|c|c|c|c|c|c|c|}
\hline \multirow[b]{2}{*}{ Sensitivity } & \multicolumn{2}{|c|}{ Control } & \multicolumn{2}{|c|}{ Nano } & \multicolumn{2}{|c|}{$C h X$} & \multirow[b]{2}{*}{ pvalue } \\
\hline & $n$ & $\%$ & $n$ & $\%$ & $n$ & $\%$ & \\
\hline \multicolumn{8}{|c|}{$\operatorname{Imm}(n=19)$} \\
\hline Score 1 & 13 & $68.4 \%$ & 13 & $68.4 \%$ & 13 & $68.4 \%$ & $1.00 \mathrm{NS}$ \\
\hline Score 2 & 6 & $31.6 \%$ & 6 & $31.6 \%$ & 6 & $31.6 \%$ & \\
\hline Score 3 & 0 & $0.0 \%$ & 0 & $0.0 \%$ & 0 & $0.0 \%$ & \\
\hline Score 4 & 0 & $0.0 \%$ & 0 & $0.0 \%$ & 0 & $0.0 \%$ & \\
\hline Score 5 & 0 & $0.0 \%$ & 0 & $0.0 \%$ & 0 & $0.0 \%$ & \\
\hline Rank & \multicolumn{2}{|c|}{$\mathrm{aA}$} & \multicolumn{2}{|c|}{$\mathrm{aA}$} & \multicolumn{2}{|c|}{$\mathrm{aA}$} & \\
\hline \multicolumn{8}{|c|}{$6 \mathrm{M}(n=17)$} \\
\hline Score 1 & 13 & $76.5 \%$ & 13 & $76.5 \%$ & 15 & $88.2 \%$ & 0.614 NS \\
\hline Score 2 & 4 & $23.5 \%$ & 4 & $23.5 \%$ & 2 & $11.8 \%$ & \\
\hline Score 3 & 0 & $0.0 \%$ & 0 & $0.0 \%$ & 0 & $0.0 \%$ & \\
\hline Score 4 & 0 & $0.0 \%$ & 0 & $0.0 \%$ & 0 & $0.0 \%$ & \\
\hline Score 5 & 0 & $0.0 \%$ & 0 & $0.0 \%$ & 0 & $0.0 \%$ & \\
\hline Rank & \multicolumn{2}{|c|}{$\mathrm{aA}$} & \multicolumn{2}{|c|}{$\mathrm{aA}$} & \multicolumn{2}{|c|}{$\mathrm{aA}$} & \\
\hline \multicolumn{8}{|c|}{$12 \mathrm{M}(n=15)$} \\
\hline Score 1 & 13 & $86.7 \%$ & 12 & $80.0 \%$ & 12 & $80.0 \%$ & 0.862 NS \\
\hline Score 2 & 2 & $13.3 \%$ & 3 & $20.0 \%$ & 3 & $20.0 \%$ & \\
\hline Score 3 & 0 & $0.0 \%$ & 0 & $0.0 \%$ & 0 & $0.0 \%$ & \\
\hline Score 4 & 0 & $0.0 \%$ & 0 & $0.0 \%$ & 0 & $0.0 \%$ & \\
\hline Score 5 & 0 & $0.0 \%$ & 0 & $0.0 \%$ & 0 & $0.0 \%$ & \\
\hline Rank & \multicolumn{2}{|c|}{$\mathrm{aA}$} & \multicolumn{2}{|c|}{$\mathrm{aA}$} & \multicolumn{2}{|c|}{$\mathrm{aA}$} & \\
\hline \multicolumn{8}{|c|}{$24 \mathrm{M}(n=15)$} \\
\hline Score 1 & 15 & $100.0 \%$ & 15 & $100.0 \%$ & 15 & $100.0 \%$ & $1.00 \mathrm{NS}$ \\
\hline Score 2 & 0 & $0.0 \%$ & 0 & $0.0 \%$ & 0 & $0.0 \%$ & \\
\hline Score 3 & 0 & $0.0 \%$ & 0 & $0.0 \%$ & 0 & $0.0 \%$ & \\
\hline Score 4 & 0 & $0.0 \%$ & 0 & $0.0 \%$ & 0 & $0.0 \%$ & \\
\hline Score 5 & 0 & $0.0 \%$ & 0 & $0.0 \%$ & 0 & $0.0 \%$ & \\
\hline Rank & \multicolumn{2}{|c|}{$\mathrm{aA}$} & \multicolumn{2}{|c|}{$\mathrm{aA}$} & \multicolumn{2}{|c|}{$\mathrm{aA}$} & \\
\hline$p$ value & \multicolumn{2}{|c|}{$0.070 \mathrm{NS}$} & \multicolumn{2}{|c|}{0.096 NS } & \multicolumn{2}{|c|}{0.078 NS } & \\
\hline
\end{tabular}


while others reported that bacteria left in the prepared cavities could survive for longer than a year especially in the presence of microleakage. ${ }^{25-27}$ Sadly, not all of the dental materials possess antibacterial properties. Therefore, the concept of toileting of the cavity is gaining wider acceptance with a variety of commercially available dentin disinfectants available in the market. ${ }^{7}$

The two main mechanisms for gaining the benefits of any antibacterial agents in conservative dentistry are either their incorporation in the dental materials or their usage as a separate entity. Their incorporation inside the materials may negatively affect the polymerization process, color, and mechanical properties. Therefore, in this study, the cavity disinfectants (antimicrobial agents) were used as a separate step before the application of the adhesive system. ${ }^{5}$ The use of cavity disinfectants with composite resin restorations appears to be material specific regarding their interactions with various dentin bonding systems. ${ }^{28}$

Deterioration of the marginal adaptation of the restorations with the use of 10-methacryloyloxydecyl dihydreogen phosphate (MDP) universal adhesive was observed after 6 and 18 months of clinical evaluation, both for the adhesive protocol with etch-andrinse (ER) and SE application modes. ${ }^{18}$ Marginal adaptation failure can lead to the occurrence of secondary caries, so it is an important factor in prediction of restorations' durability. ${ }^{16}$

In this study, the results of marginal adaptation in different groups at different evaluation intervals showed no statistically significant difference among all groups. The same results applied to other criteria (marginal staining and postoperative sensitivity). This means that after 1 year of clinical service, usage of the two surface pretreatment (NanoCare Gold and chlorhexidine) did not produce an obvious difference.

Regarding NanoCare Gold and its ingredients, its application is supported for many reasons: the antibacterial properties without any risk of bacterial resistance and ${ }^{29,30}$ absence of any interference with bond strength, ${ }^{31-33}$ improving the wetting of the adhesive system. ${ }^{34}$ AgNPs enhance the physical properties of some dental materials. ${ }^{35,36}$

The discoloration produced by AgNPs is minute compared to silver nitrate and silver diamine. ${ }^{37}$ AuNPs inhibit MMP 1, 2, 8, and 9. ${ }^{38-41}$ AuNPs have a weak or no antimicrobial effect against many species but their mixtures with other antimicrobial agents enhance the bactericidal properties of these agents. ${ }^{29}$

Borczyk and Pietranek found that the application of NanoCare Gold before placement of resin composite results in the formation of a layer of silver and gold NPs in the interface between the tooth cavity and the restoration. ${ }^{42}$ Their presence in this area resists the development of bacteria in the microgaps and consequently reduces the risk of caries recurrence. They also mentioned that isopropyl alcohol reduces the surface tension to reach the smallest dentinal tubule and dry the cavity in addition to its antiseptic properties.

According to Porenczuk et al. and Ramasetty et al., the application of NanoCare Gold did not affect the bond strength to dentin, but the mode of failure changed after its application. This change varies according to the sequence of application of materials (either before or after cavity priming). When applied after primer, the mode of failure is either mixed or adhesive with the same frequency while when applied before priming step, adhesive failure is reduced by $34 \%{ }^{4,15}$

NanoCare Gold enlarges the bonding area for the adhesive system; this may be due to the formation of a homogenous layer of NPs on the surface after alcohol evaporation. ${ }^{15}$ Alcohols can act as MMPs inhibitors especially MMP-9 and endogenous proteases of dentin matrix in a dose-dependent manner. High alcohol concentrations may denature enzymes by removing water from the enzyme structure, causing their denaturation..$^{19,43}$

Durner et al. and Sokołowski et al. are against the AgNPs as it could affect the polymerization process in dental materials and deterioration of resin-filler interactions so the materials are more susceptible to leaching of components and grayish discoloration of the materials. ${ }^{29,44}$

Chlorohexidine is considered the gold standard in cavity disinfection due to its antimicrobial properties and inhibition of MMPs. ${ }^{22,45,46}$ In an ex vivo study by Carrilho et al., after 14 months in vivo, cohesive failure within the hybrid layer was more frequently observed in untreated samples compared to that treated with $2 \%$ chlorhexidine. ${ }^{47}$ Soares et al., Sartori et al., and Jowkar et al. are supportive to the positive effect of its application and mentioned that its application in deep carious cavities increases the clinical success of direct and indirect pulp capping procedures. $5,48,49$

In addition to the ability of chlorohexidine to produce partial removal of smear layer (removes the loose smear debris), it provides slight opening of dentinal tubules orifices. This may enhance the penetration of the acidic monomers of the self-etch adhesive. This also converts the smear layer from loosely to firmly bonded layer that minimizes convective and evaporative water fluxes from the underlying dentin, which enhances the bonding capacity of the adhesive. ${ }^{50}$ Its application increases the surface energy of dentin, which increases the dentin-wetting ability of the adhesive and provides better chance for chemical interaction. ${ }^{26}$

Chlorohexidine can increase the bond durability of mild universal adhesives. ${ }^{3}$ One of the important points is the effect of chlorohexidine on the degree of conversion of the adhesive systems; it was reported that chlorohexidine at concentrations ranging from 0.5 to $2 \%$ did not affect the degree of conversion of resinous monomers in adhesive systems. ${ }^{46}$

Although clinical trials remain the ultimate tool, preclinical evaluation of materials is still important. However, it is not fully understood whether there is a relationship between laboratory data and clinical outcomes but nearly there is a consensus that dentin pretreatment with chlorohexidine showed a higher bond strength values in aged samples compared to untreated dentin. ${ }^{51}$ Both selfetch and etch-and-rinse systems showed to be benefited by the chlorohexidine in vitro. ${ }^{22}$ The controversial results among studies may be due to the different dentin adhesive systems used (different types of self-etch and total-etch adhesives) and these adhesives may be acetone-based or ethanol-based. ${ }^{52}$

Singla et al. are against the disinfection of cavities with chlorohexidine and justify this by the nature of the layer formed on dentin surface after application of cavity disinfectant that was resistant to acidic conditioning and might inhibit the ability of the weak acidic primer to effectively demineralize dentin and hydrophilic resin to impregnate the dentinal surface and decreases dentin wettability. ${ }^{53}$ Chlorhexidine usage with self-etch adhesive causes a more pronounced nano leakage. ${ }^{50}$

Chlorohexidine is washed away from the hybrid layer during $1-2$ years, resulting in collagen degradation. The adverse effect of $2 \%$ chlorohexidine on bond strength of self-etch adhesives may be due to the presence of functional monomer (MDP), which is not compatible with chlorohexidine. ${ }^{20}$

According to Göstemeyer and Schwendicke, the clinical data in usage of chlorohexidine do not convincingly support the idea 
of surface pretreatment for the sake of reduction of retention loss or restoration failure. This is due to the effect of attrition in some studies, great uncertainty of their effect (benefits, harm), so far the longest follow-up was 36 months, presence of confounders in the available clinical trials such as type of substrate (carious, noncarious), type of dentition (deciduous, permanent), moisture control tools (rubber dam, cotton roll), type of adhesive system (etch and rinse, self-etch), concentration of chlorohexidine, and cavity size. Another issue is the quality of evidence due to the absence of blindness (operator, patient, and examiner), allocation concealment, limited sample size, short follow-up period, attrition rate, safety aspect (pulpal status), clinical applicability, and cost-effectiveness of the additional treatment step. ${ }^{54}$

Montagner et al. tested chlorohexidine clinically in the adhesive step and did not present any benefit of its use. ${ }^{11,22}$ Favetti et al. tested the effect of chlorohexidine on restoration retention (noncarious cervical lesions, 3 years trial, etch and rinse, 60 seconds, FDI criteria). ${ }^{2}$ They found that chlorohexidine did not promote further retention or any beneficial effect to the clinical performance of restorations in this condition. In another clinical trial, $2 \%$ chlorhexidine solution was used before acid etching in the ER and SE and before the application of the adhesive in the SE group. ${ }^{18}$ According to Sartori et al., after 3 years of follow-up, chlorohexidine application to acid-etched dentin does not improve the clinical durability of noncarious cervical lesions. ${ }^{49}$ Moraes et al. in a 2 years clinical trial found that the addition of chlorohexidine into adhesive systems or its use as dentin pretreatment did not add clinical advantages and did not improve the clinical durability of adhesive restorations. ${ }^{43}$

The effect of dentin pretreatment with AgNPs on the bond strength was comparable to that of chlorohexidine for the etch-andrinse adhesive system and better than that of chlorohexidine for the self-etch adhesive system. This was referred to the hydrophilic nature of AgNPs which increases the surface tension of the dentin surface and improves the inadequate penetration of the adhesive system through dentin, in addition to the capability of silver to form compounds with oxide, phosphate, chloride, and proteins with a relatively low solubility inside dentinal tubules. This may lead to a gradual and long-lasting release of small amounts of silver ions, providing long-term antibacterial efficacy at the adhesive-tooth interface. $^{5}$

Torres et al. reported that postoperative sensitivity may be affected by factors like polymerization shrinkage and failures in the polymerization of the deep portions of the resinous layers. Sensitivity to cold commonly occurs during mastication and the first week after insertion of the restoration. ${ }^{16}$

Regarding the results of demographic data in this study, there was no significant difference in age, gender, arch, and tooth type distribution among study groups. These results are in agreement with results of Maurer et al. that there was no difference in occlusion between males and females and consequently a difference in the performance of the restorations ${ }^{55}$ while Koç et al. found that bite force was significantly higher in men than women due mostly to the greater muscular potential of men. ${ }^{56}$

Also, males have type-Il fibers in the masseter muscle, which have larger diameter. Tripathi et al. confirmed that dental component of males is also larger than in females which in turn increases the periodontal support further contributing to increased biting force. ${ }^{57}$ These differences among studies may be due to the difference in the number of males and females included in the studies. Krämer et al. mentioned that location of restorations either in the upper or lower jaw had no effect on clinical outcome after 6 years. ${ }^{1}$ In general, deterioration of restorations is more pronounced in molars than premolars, especially the lower molars based on von Spee's curve. This mainly occurs due to enamel cracks and chippings that increase with time. ${ }^{13}$

Clinical research is a faithful and relevant method to evaluate the performance of dental restorations, as it analyses the actual influence of masticatory forces, as well as the salivary enzymes and bacterial action on the evaluated material and technique. With split-mouth design, two or more interventions are tested in the same patient. It is possible to obtain more realistic results since all treatments will receive the same type of load and protocols; thus, the interindividual variability is minimized. According to Carvalho et al., split-mouth study design was performed so that the same participant could receive the three groups to be evaluated. ${ }^{18}$ While the disadvantage of split-mouth following Balkaya et al. is that the possible patient loss means loss of more than one restoration. $^{13}$

FDI World Dental Federation criteria were created in 2007 and modified in 2010 and have been widely used in current clinical studies. These criteria are more sensitive to small variations and for short follow-up durations, being able to detect smaller differences between the restorations when compared with the criteria proposed by the United States Public Health Service (USPHS) especially in the marginal adaptation parameter. ${ }^{18,24}$ Therefore, it was selected as the method of choice used in this study to evaluate dental restorations. ${ }^{16}$

Short follow-up period is one of the limitations of this study. Although long-term follow-up is important to compare and evaluate the clinical performance of different interventions, shortterm clinical data can also give some useful information about the clinical performance of the materials. Although this study is a short-term clinical study, the patients will continue to be followed up for additional longer durations.

The combination of strategies to improve bond durability of adhesive systems with improved oral health care and patient motivation is the key for success of adhesive restorations. ${ }^{9}$

\section{Recommendations}

The effect of the two cavity disinfectants may be manifested after a longer follow-up period to determine is it worthy to add an extra step to the ordinary steps or not. Further studies are needed to detect the impact of NanoCare Gold cavity disinfectant on bacterial count, adjacent mucosa, general oral health, and prevention of new carious lesions.

\section{Conclusion}

NanoCare Gold could be promising in durability preservation of direct tooth-colored restorations. Marginal staining and postoperative sensitivity are regulated by other factors than surface pretreatment.

\section{Research Ethics Committee Approval}

The protocol of the current study was registered in www. clinicaltrials.gov, with unique identification number NCT03669224. All procedures performed in this study, involving human participants, were in accordance with the ethical standards of Research Ethics Committee of Faculty of Dentistry, Cairo University (CREC) \# 42-9-18. 


\section{Consent Statement}

An informed consent with an easy Arabic language was signed by the recruited participants.

\section{References}

1. Krämer N, García-Godoy F, Reinelt C, et al. Nanohybrid vs. fine hybrid composite in extended class II cavities after six years. Dent Mater 2011;27(5):455-464. DOI: 10.1016/j.dental.2011.01.004.

2. Favetti M, Schroeder T, Montagner AF, et al. Effectiveness of pretreatment with chlorhexidine in restoration retention: a 36-month follow-up randomized clinical trial. J Dent 2017;60:44-49. DOI: 10.1016/j.jdent.2017.02.014.

3. Tekçe N, Tuncer S, Demirci M, et al. Do matrix metalloproteinase inhibitors improve the bond durability of universal dental adhesives? Scanning 2016;38(6):535-544. DOI: 10.1002/sca.21293.

4. Ramasetty PA, Tripathi AP, Sugandhan S, et al. Nanotechnology in dentin disinfection: can we preserve the bond? Int J Clin Pediatr Dent 2018;11(6):468-473. DOI: 10.5005/jp-journals-10005-1559.

5. Jowkar Z, Shafiei F, Asadmanesh E, et al. Influence of silver nanoparticles on resin-dentin bond strength durability in a selfetch and an etch-and-rinse adhesive system. Restor Dent Endod 2019:44(2):e13. DOI: 10.5395/rde.2019.44.e13.

6. Lukomska-Szymanska M, Zarzycka B, Sokolowski K, et al. Nanosilver dispersion in alcohol-antibacterial properties. E-Dentico 2013;1(41):66-75.

7. Elgamily HM, El-Sayed HS, Abdelnabi A. The antibacterial effect of two cavity disinfectants against one of cariogenic pathogen: an in vitro comparative study. Contemp Clin Dent 2018;9(3):457-462. DOI: 10.4103/ccd.ccd_308_18.

8. Hickel R, Peschke A, Tyas M, et al. FDI World Dental Federation: clinical criteria for the evaluation of direct and indirect restorations-update and clinical examples. Clin Oral Investig 2010;14(4):349-366. DOI: 10.1007/s00784-010-0432-8.

9. Carvalho RM, Manso AP, Geraldeli S, et al. Durability of bonds and clinical success of adhesive restorations. Dent Mater 2012;28(1):72-86. DOI: 10.1016/j.dental.2011.09.011.

10. Marquillier T, Doméjean S, Le Clerc J, et al. The use of FDI criteria in clinical trials on direct dental restorations: a scoping review. J Dent 2018;68:1-9. DOI: 10.1016/j.jdent.2017.10.007.

11. Montagner AF, Perroni AP, Corrêa MB, et al. Effect of pre-treatment with chlorhexidine on the retention of restorations: a randomized controlled trial. Braz Dent J 2015;26(3):234-241. DOI: 10.1590/01036440201300009

12. de Paula EA, Tay LY, Kose C, et al. Randomized clinical trial of four adhesion strategies in cervical lesions: 12-month results. Int J Esthet Dent 2015;10(1):122-145. PMID: 25625130.

13. Balkaya H, Arslan S, Pala K. A randomized, prospective clinical study evaluating effectiveness of a bulk-fill composite resin, a conventional composite resin and a reinforced glass ionomer in Class II cavities: one-year results. J Appl Oral Sci 2019;27:e20180678. DOI: 10.1590/1678-7757-2018-0678.

14. Loguercio $A D$, Rezende M, Gutierrez MF, et al. Randomized 36-month follow-up of posterior bulk-filled resin composite restorations. J Dent 2019;85:93-102. DOI: 10.1016/j.jdent.2019.05.018.

15. Porenczuk A, Firlej P, Szczepańska G, et al. The laboratory comparison of shear bond strength and microscopic assessment of failure modes for a glass-ionomer cement and dentin bonding systems combined with silver nanoparticles. Acta Bioeng Biomech 2016;18(2):59-70. PMID: 27405339.

16. Torres CRG, Mailart MC, Crastechini É, et al. A randomized clinical trial of class II composite restorations using direct and semidirect techniques. Clin Oral Investig 2020;24(2):1053-1063. DOI: 10.1007/ s00784-019-02999-6.

17. Perdigão J, Kose C, Mena-Serrano AP, et al. A new universal simplified adhesive: 18-month clinical evaluation. Oper Dent 2014;39(2):113-127. DOI: 10.2341/13-045-C.
18. Carvalho AA, Leite MM, Zago JKM, et al. Influence of different application protocols of universal adhesive system on the clinical behavior of Class I and II restorations of composite resin-a randomized and double-blind controlled clinical trial. BMC Oral Health 2019;19(1):252-262. DOI: 10.1186/s12903-019-0913-3.

19. Zhou W, Liu S, Zhou X, et al. Modifying adhesive materials to improve the longevity of resinous restorations. Int J Mol Sci 2019;20(3):723. DOI: 10.3390/ijms20030723.

20. Davalloo R, Tavangar SM, Ebrahimi H, et al. In vitro comparative evaluation of newly produced desensitizer, chlorhexidine and Gluma on bond strength and bond longevity of composite to dentin. J Dent (Shiraz) 2020;21(2):111-118. DOI: 10.30476/DENTJODS.2019.77756.0.

21. Spencer $P$, Jonggu Park QY, Misra $A$, et al. Durable bonds at the adhesive/dentin interface: an impossible mission or simply a moving target? Braz Dent Sci 2012;15(1):4-18. DOI: 10.14295/bds.2012. v15i1.790.

22. Montagner AF, Sarkis-Onofre R, Pereira-Cenci T, et al. MMP inhibitors on dentin stability: a systematic review and meta-analysis. J Dent Res 2014;93(8):733-743. DOI: 10.1177/0022034514538046.

23. Lapinska B, Konieczka M, Zarzycka B, et al. Flow cytometry analysis of antibacterial effects of universal dentin bonding agents on Streptococcus mutans. Molecules 2019;24(3):532. DOI: 10.3390/ molecules24030532.

24. Manarte-Monteiro $P$, Domingues J, Teixeira $L$, et al. Multi-Mode adhesives performance and success/retention rates in NCCLs restorations: randomized clinical trial one-year report. Biomater Investig Dent 2019;6(1):43-53. DOI: 10.1080/26415275.2019.1684199.

25. Sharma V, Rampal P, Kumar S. Shear bond strength of composite resin to dentin after application of cavity disinfectants-SEM study. Contemp Clin Dent 2011;2(3):155-159. DOI: 10.4103/0976-237X. 86438.

26. Elkassas DW, Fawzi EM, El Zohairy A. The effect of cavity disinfectants on the micro-shear bond strength of dentin adhesives. Eur J Dent 2014;8(2):184-190. DOI: 10.4103/1305-7456.130596.

27. Bin-Shuwaish MS. Effects and effectiveness of cavity disinfectants in operative dentistry: a literature review. J Contemp Dent Pract 2016;17(10):867-879. DOI: 10.5005/jp-journals-10024-1946.

28. Campos EA de, Correr GM, Leonardi DP, et al. Influence of chlorhexidine concentration on microtensile bond strength of contemporary adhesive systems. Braz Oral Res 2009;23(3):340-345. DOI: 10.1590/s1806-83242009000300019.

29. Sokołowski J, Szynkowska MI, Kleczewska J, et al. Evaluation of resin composites modified with nanogold and nanosilver. Acta Bioeng Biomech 2014;16(1):51-61. PMID: 24708202.

30. Subbiah $\mathrm{G}$, Gopinathan N. Is silver diamine fluoride effective in preventing and arresting caries in elderly adults? A systematic review. J Int Soc Prev Community Dent 2018;8(3):191-199. DOI: 10.4103/jispcd. JISPCD_99_18.

31. Melo MAS, Cheng L, Weir MD, et al. Novel dental adhesive containing antibacterial agents and calcium phosphate nanoparticles. J Biomed Mater Res B Appl Biomater 2013;101(4):620-629. DOI: 10.1002/ jbm.b.32864.

32. Melo MAS, Cheng L, Zhang K, et al. Novel dental adhesives containing nanoparticles of silver and amorphous calcium phosphate. Dent Mater 2013;29(2):199-210. DOI: 10.1016/j.dental.2012.10.005.

33. de Oliveira Reis B, de Lima Godas AG, Suzuki TYU, et al. Do different pretreatments of dentine surface affect the bond strength with a self-adhesive resin cement? Oral Health Prev Dent 2020;18(1):145-152. DOI: 10.3290/j.ohpd.a43355.

34. Torres-Méndez F, Martinez-Castañon G-A, Torres-Gallegos I, et al. Effects of silver nanoparticles on the bonding of three adhesive systems to fluorotic enamel. Dent Mater J 2017;36(3):266-274. DOI: 10.4012/dmj.2015-299.

35. Mackiewicz A, Olczak-Kowalczyk D. Microscopic evaluation of surface topography and chemical composition of Nanocare Gold. J Stomatol 2015;67(6):826-840. DOI: 10.5604/00114553.1137107

36. Porenczuk A, Grzeczkowicz A, Maciejewska I, et al. An initial evaluation of cytotoxicity, genotoxicity and antibacterial effectiveness of 
a disinfection liquid containing silver nanoparticles alone and combined with a glass-ionomer cement and dentin bonding systems. Adv Clin Exp Med 2019;28(1):75-83. DOI: 10.17219/acem/76160.

37. Besinis A, De Peralta T, Handy RD. Inhibition of biofilm formation and antibacterial properties of a silver nano-coating on human dentine. Nanotoxicology 2014;8(7):745-754. DOI: 10.3109/17435390.2013.825343.

38. Hashimoto M, Sasaki Jl, Yamaguchi S, et al. Gold nanoparticles inhibit matrix metalloproteases without cytotoxicity. J Dent Res 2015;94(8):1085-1091. DOI: 10.1177/0022034515589282.

39. Hashimoto M, Kawai K, Kawakami H, et al. Matrix metalloproteases inhibition and biocompatibility of gold and platinum nanoparticles. J Biomed Mater Res A 2016;104(1):209-217. DOI: 10.1002/jbm.a.35557.

40. Hashimoto M, Yamaguchi S, Sasaki J-I, et al. Inhibition of matrix metalloproteinases and toxicity of gold and platinum nanoparticles in L929 fibroblast cells. Eur J Oral Sci 2016;124(1):68-74. DOI: 10.1111/ eos.12235.

41. Hashimoto M, Kawakami H, Kawai K, et al. Effect of particle size of gold nanoparticles on matrix metalloprotease inhibition, cytotoxicity and genotoxicity. J Biomater Tissue Eng 2017;7(2):139-146. DOI: 10.1166/ jbt.2017.1555.

42. Borczyk R, Pietranek K. Nanocare Gold preparation in the prevention of recurrent caries. Mag Stomatol 2009;(10):62-66.

43. de Moraes IQS, do Nascimento TG, da Silva AT, et al. Inhibition of matrix metalloproteinases: a troubleshooting for dentin adhesion. Restor Dent Endod 2020;45(3):e31. DOI: 10.5395/rde.2020. 45.e31.

44. Durner J, Stojanovic M, Urcan E, et al. Influence of silver nano-particles on monomer elution from light-cured composites. Dent Mater 2011;27(7):631-636. DOI: 10.1016/j.dental.2011.03.003.

45. Cheng L, Weir MD, Xu HHK, et al. Antibacterial and physical properties of calcium-phosphate and calcium-fluoride nanocomposites with chlorhexidine. Dent Mater 2012;28(5):573-583. DOI: 10.1016/ j.dental.2012.01.006.

46. Dos Santos RA, de Lima EA, Montes MAJR, et al. Pre-treating dentin with chlorhexadine and CPP-ACP: self-etching and universal adhesive systems. Acta Biomater Odontol Scand 2016;2(1):79-85. DOI: 10.1080/23337931.2016.1203265.
47. Carrilho MRO, Geraldeli S, Tay F, et al. In vivo preservation of the hybrid layer by chlorhexidine. J Dent Res 2007;86(6):529-533. DOI: $10.1177 / 154405910708600608$.

48. Soares CJ, Pereira JC, Souza SJB, et al. The effect of prophylaxis method on microtensile bond strength of indirect restorations to dentin. Oper Dent 2012;37(6):602-609. DOI: 10.2341/11-459-L.

49. Sartori N, Stolf SC, Silva SB, et al. Influence of chlorhexidine digluconate on the clinical performance of adhesive restorations: a 3-year follow-up. J Dent 2013;41(12):1188-1195. DOI: 10.1016/j. jdent.2013.09.004.

50. Cha H-S, Shin D-H. Antibacterial capacity of cavity disinfectants against Streptococcus mutans and their effects on shear bond strength of a self-etch adhesive. Dent Mater J 2016;35(1):147-152. DOI: 10.4012/dmj.2015-175.

51. Gunaydin Z, Yazici AR, Cehreli ZC. In vivo and in vitro effects of chlorhexidine pretreatment on immediate and aged dentin bond strengths. Oper Dent 2016;41(3):258-267. DOI: 10.2341/14-231-C.

52. Kim B-R, Oh M-H, Shin D-H. Effect of cavity disinfectants on antibacterial activity and microtensile bond strength in class I cavity. Dent Mater J 2017;36(3):368-373. DOI: 10.4012/dmj.2016-283.

53. Singla M, Aggarwal V, Kumar N. Effect of chlorhexidine cavity disinfection on microleakage in cavities restored with composite using a self-etching single bottle adhesive. J Conserv Dent 2011;14(4):374-377. DOI: 10.4103/0972-0707.87201.

54. Göstemeyer G, Schwendicke F. Inhibition of hybrid layer degradation by cavity pretreatment: meta- and trial sequential analysis. J Dent 2016;49:14-21. DOI: 10.1016/j.jdent.2016.04.007.

55. Maurer $C$, Holzgreve F, Erbe $C$, et al. Influence of dental occlusion conditions on plantar pressure distribution during standing and walking-a gender perspective. Med Eng Phys 2021;88:47-53. DOI: 10.1016/j.medengphy.2020.12.011.

56. Koç D, Doğan A, Bek B. Effect of gender, facial dimensions, body mass index and type of functional occlusion on bite force. J Appl Oral Sci 2011;19(3):274-279. DOI: 10.1590/S1678-77572011000300017.

57. Tripathi G, Ponnanna AA, Rajwadha N, et al. Comparative evaluation of maximum bite force in dentulous and edentulous individuals with different facial forms. J Clin Diagn Res 2014;8(9):ZC37-ZC40. DOI: 10.7860/JCDR/2014/8801.4837. 